\title{
Professorial roles for dentists fall 8.3\% since 2015
}

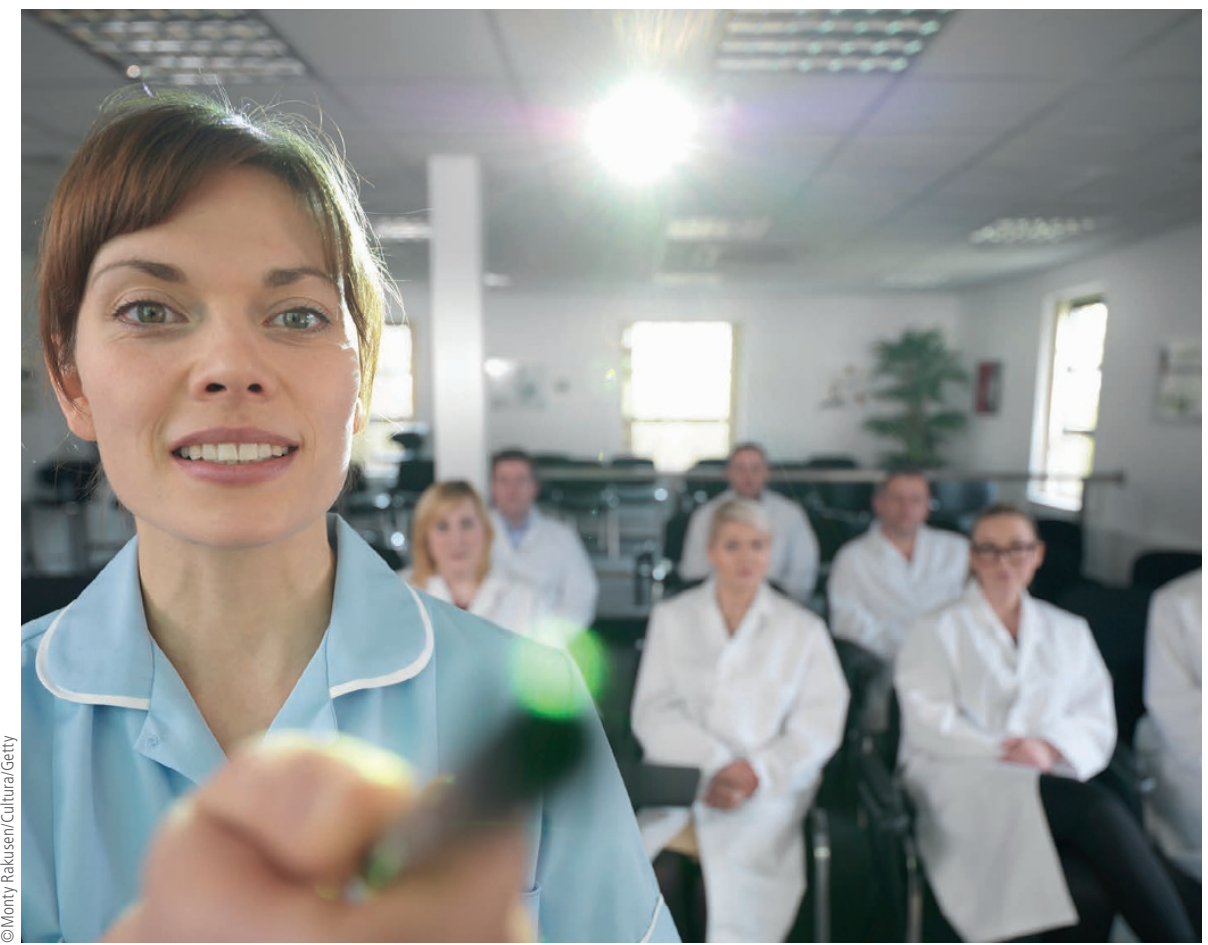

Numbers of dentists teaching at professorial level have dropped by almost $10 \%$ since 2015, but overall academic staff numbers are growing, according to new figures from the Dental Schools Council.

The Council published its annual report ${ }^{1}$ on the state of the dental clinical academic workforce on 3 August 2018 in which it revealed that the number of clinical academics at professorial level had continued to decline by $8.3 \%$ since 2015 from 117 full-time equivalent professors to 107.2.

However, there was a continued increase in the number of full-time clinical academic staff.

The results of the survey of clinical academic staffing levels show that on 31 July 2017 (the latest period measured), there were 607.3 full-time equivalent (FTE) clinical academics employed at UK dental schools - a $2.2 \%$ increase in staffing since 2016 , and a $40 \%$ rise since 2004 .

This is the sixteenth data update to be published by the Dental Schools Council since 2000 and 18 UK dental schools returned data on clinical academic grade, specialty, percentage full-time, Clinical Excellence Award, source of funding, age, gender, and ethnicity for each individual in post.

The latest annual report is supported by a new interactive tool ${ }^{2}$ to ensure easier data analysis for researchers.
The report also shows there is instability of staff on research-active contracts with a decline between 2016 and 2017 of professors, and only small recoveries for reader/ senior lecturer and lecturer staff on previous periods of decline since 2004 .

However, these losses were compensated, said the Council, by the introduction and rise in teaching-only staff, so instead of an overall loss, this could be seen as an evolution of the clinical academic team to a sharper focus on teaching.

Professor Chris Deery, Chair of the Dental Schools Council, said: 'The continued increase in the number of clinical academic staff is a testament to the work that has been done, particularly by dental schools, to showcase the benefit clinical academia brings to UK dental care.

'As this year's data highlights, there is clearly much more left to do, especially in regard to filling vacancies. We are all too aware of the pressures on our health service and we need these talented individuals in roles that lead the way to more efficient and effective healthcare.

'The increase has focused on teaching roles and we need to also protect research activity, as, in addition to the healthcare benefits these researchers bring to oral and general health, there is no substitute for research-led teaching at a university level.'
The BDA said that although there had been a $2.2 \%$ rise in the number of full-time clinical academic staff employed since 2016, dental schools were increasingly relying on part-time staff with a concentration in teaching posts over research. The workforce figures revealed a steady increase in employing part-time staff in the last five years, from $57 \%$ of the workforce in 2013 to $59 \%$ in 2017 . The picture since 2004 was starker, when the less-than-full-time figure was $44 \%$.

The BDA said the decline in research posts was a direct threat to the profession being able to find and explore new treatments, and could lead to an unhealthy period of stagnation, particularly if work was being done in other countries which would eclipse the UK's reputation in research.

This overall shift from research to teaching contracts meant UK dental academia could beome little more than a 'degree mill'.

The report also warned that more than two-thirds of the dental schools - 13 out of 18 - had experienced difficulties in recruiting to one or more specialities.

Giles McCracken, the Chair of the Central Committee for Dental Academic Staff, said: 'The latest figures on the workforce in dental schools show a worrying trend towards employing part-time staff to teach at the expense of research. This is incredibly shortsighted and mechanistic and undermines the global reputation that dental schools in the UK have enjoyed till now.

'Without the capacity for research, UK dental schools will have ongoing problems attracting top-class staff and this will impact upon the future of the profession.

'Advances in dentistry require ongoing investment in our research talent, not aspirational platitudes. The Dental Schools Council needs to do more to attract the top talent to deliver not just quality teaching but also world class dental research and thereby ensure the health of the profession in the long term.'

1. Dental Schools Council. Survey of Dental Clinical Academic Staffing Levels: A report by the Dental Schools Council 2018. August 2018. www.dentalschoolscouncil. ac.uk/wp-content/uploads/2018/08/clinical-academic-survey-dental-2018.pdf (accessed 13 August 2018)

2. Dental Schools Council. Interactive Tool. www.dentalschoolscouncil.ac.uk/academic-dentistry/clinical-academic-staff-survey/section-1-overview (accessed 13 August 2018). 